\title{
A BioMEMS Review: MEMS Technology for Physiologically Integrated Devices
}

\author{
AMY C. RICHARDS GRAYSON, REBECCA S. SHAWGO, AUDREY M. JOHNSON, \\ NOLAN T. FLYNN, YAWEN LI, MICHAEL J. CIMA, AND ROBERT LANGER
}

Invited Paper

\begin{abstract}
MEMS devices are manufactured using similar microfabrication techniques as those used to create integrated circuits. They often, however, have moving components that allow physical or analytical functions to be performed by the device. Although MEMS can be aseptically fabricated and hermetically sealed, biocompatibility of the component materials is a key issue for MEMS used in vivo. Interest in MEMS for biological applications (BioMEMS) is growing rapidly, with opportunities in areas such as biosensors, pacemakers, immunoisolation capsules, and drug delivery. The key to many of these applications lies in the leveraging of features unique to MEMS (for example, analyte sensitivity, electrical responsiveness, temporal control, and feature sizes similar to cells and organelles) for maximum impact. In this paper, we focus on how the biological integration of MEMS and other implantable devices can be improved through the application of microfabrication technology and concepts. Innovative approaches for improved physical and chemical integration of systems with the body are reviewed. An untapped potential for MEMS may lie in the area of nervous and endocrine system actuation, whereby the ability of MEMS to deliver potent drugs or hormones, combined with their precise temporal control, may provide new treatments for disorders of these systems.
\end{abstract}

Keywords-Biomedical engineering, biomedical materials, biomedical transducers, drug delivery systems, microelectromechanical devices, micromachining, microneedles, microparticles, cardiac pacemakers, surface modification, tissue engineering.

Manuscript received February 3, 2003; revised April 10, 2003. This work was supported by National Institutes of Health Bioengineering Research Partnership under Grant R24-AI47739.

A. C. R. Grayson is currently with the School of Chemical and Biomolecular Engineering and the Biomedical Engineering Program, Cornell University, Ithaca, NY 14853 USA (e-mail: acg37@ cornell.edu).

R. S. Shawgo, Y. Li, and M. J. Cima are with the Department of Materials Science and Engineering, Massachusetts Institute of Technology, Cambridge, MA 02139 USA (e-mail: acrichar@mit.edu; shawgo@mit.edu; ywli@mit.edu; mjcima@mit.edu).

A. M. Johnson and R. Langer are with the Department of Chemical Engineering, Massachusetts Institute of Technology, Cambridge, MA 02139 USA (e-mail: cameo@mit.edu; nflynn@mit.edu; rlanger@mit.edu).

N. T. Flynn is with the Department of Chemistry, Wellesley College, Wellesley, MA 02481 USA.

Digital Object Identifier 10.1109/JPROC.2003.820534

\section{INTRODUCTION}

Microelectromechanical systems (MEMS) devices are manufactured using similar microfabrication techniques as those used to create integrated circuits. They often have moving components that allow a physical or analytical function to be performed by the device in addition to their electrical functions. Microfabrication of silicon-based structures is usually achieved by repeating sequences of photolithography, etching, and deposition steps in order to produce the desired configuration of features, such as traces (thin metal wires), vias (interlayer connections), reservoirs, valves, or membranes, in a layer-by-layer fashion. The interested reader is directed to [1]-[3] for a review of microfabrication techniques. Microelectronics fabrication techniques routinely produce well-controlled features that range in size from millimeters to submicrometers, while soft lithography techniques were recently used to produce features below $100 \mathrm{~nm}$ [4]. Although a vast assortment of MEMS components and devices, including microreservoirs, micropumps, cantilevers, rotors, channels, valves, sensors, and other structures, have been fabricated and tested in the laboratory environment, most devices are designed for in vitro diagnostics.

Interest in using MEMS and microfabrication technologies for in vivo applications, however, is growing. MEMS can be aseptically fabricated and hermetically sealed, and the biocompatibility of materials used in MEMS fabrication is being investigated. The manufacturing techniques used in the microelectronics industry may lead to greater uniformity and reproducibility of implantable devices than is currently available to the biomedical and pharmaceutical industries. MEMS offer great potential advantages over other types of implantable systems for certain applications due to their small size scale, electrical nature, and ability to operate on short time scales. The development of retinal implants to treat blindness, neural implants for stimulation and recording from the central nervous system, and microneedles for painless vaccination are examples of applications 
in which features unique to MEMS, such as optical and electrical sensitivity or feature size comparable to relevant biological structures, are being leveraged for maximum impact.

The digital capabilities of MEMS may allow potentially greater temporal control in the area of drug delivery than can currently be achieved with polymer-based systems. Additionally, the incorporation of optical, electrical, or chemical sensing components into MEMS devices can allow the delivery of drugs to be attuned to changes in the physiological environment surrounding the device. A number of researchers have pursued a similar strategy for the incorporation of sensing components into responsive polymeric systems for drug delivery, including systems that can be triggered by the application of ultrasound [5], [6], changes in $\mathrm{pH}$ [7]-[12], temperature [13]-[18], analyte concentrations [19]-[21], and electric [22]-[27] or magnetic [28], [29] fields. While these systems are useful and interesting in their own right, we will not discuss them in detail, as they largely fall outside the scope of this paper.

The small size of MEMS, coupled with their ability to achieve precise control over the timing of drug delivery, may prove to be of great utility in the area of actuation of physiological systems within the human body. Molecules such as hormones or growth factors are often quite potent, and their effect is strongly influenced by their temporal administration. These potent molecules affect signaling and regulatory systems in the body, such as the endocrine and nervous systems. The ability of MEMS to act on a short time scale and under physiologically relevant conditions, coupled with their ability to deliver an electrical stimulus and/or drugs from a device, offer the potential for these devices to actuate systems in the body.

We focus in this paper on the idea of physiological integration of MEMS, which encompasses two main concepts. First, we will examine how the physiological integration of MEMS and other implantable devices can be improved through the application of microfabrication technology and concepts, and we review the current state of the art in the assessment and improvement of MEMS biocompatibility. In some cases, such as the microtexturing of surfaces for better cell adhesion, greater physical integration of the device can be achieved with the in vivo environment. In other cases, the chemical interaction between the device and biological environment can be improved, such as through the surface functionalization of devices with protein-resistant moieties, or alternatively the patterning of cell-adhesive molecules. Second, we will present a new perspective on the ability of MEMS to actuate various systems within the body, taking as our example pacemakers and cardiology devices. We suggest that the application of MEMS and microfabrication technology may enable better logistical and physiological integration with the delicate systems of the human body than is currently available in clinical or commercial treatments, such as for actuation of the endocrine system. One can envision the utility of MEMS as a uniquely powerful platform for delivering potent therapeutic agents whose temporal administration is vital to their efficacy, and whose effect is naturally amplified by the human body.

\section{IMPLANTABLE MEMS}

A variety of implantable electronic devices are based upon or use MEMS technology, including sensors, immunoisolation capsules, and drug delivery microchips. These topics, as well as a novel application of microfabrication technology to stents, are briefly reviewed here.

\section{A. Biosensors}

Much has been done in the application of MEMS technology to biosensors and the adaptation of various types of sensors to in vivo diagnostics. However, at the intersection of these fields, namely, implantable MEMS biosensors, there are few examples. This is due in part to the formidable challenges faced in the more general field of implantable biosensors. The goal of short-term sensing of $\mathrm{pH}$, analytes, and pressure in blood, tissue, and body fluids has largely been achieved, but stable sensors for long-term implantation continue to elude researchers [30]-[34]. Long-term in vivo sensing is a critical component of the ideal closed-loop drug delivery or monitoring system, but the issue of implant biocompatibility and biofouling must be addressed in order to achieve long-term in vivo sensing. Although it is important to avoid adverse tissue responses to any implant, the degree of biocompatibility must be greater for a sensor.

Even those materials generally considered to be biocompatible produce some degree of tissue response, usually resulting in the partial isolation of the implant from the body. Although this typically does not impede the function of drug delivery, orthopedic, or other implants whose function is essentially mechanical in nature, implant isolation leads to reduced sensitivity and increased delay time for a sensor. The same biocompatibility challenge must be overcome by any MEMS biosensor for in vivo use, as the intimate interaction of sensor and analyte is intrinsic to the operation of all sensors. Efforts are under way to use microfabricated biosensors in vivo, especially for the less problematic short-term sensing applications. Sensing strategies for biosensors include optical [35], mechanical [36], magnetic [37], and electrochemical [38], [39] detection methods, as well as combinations of the above. For example, both optical and electrochemical sensors have been developed to monitor local $\mathrm{pH}$ in brain tissue and in blood [40], [41]. A multiparameter sensor has been reported that combines electrochemical and fiber-optic technology for continuous in vivo measurement of $\mathrm{pH}$, carbon dioxide partial pressure, oxygen partial pressure, and oxygen saturation early in human pregnancy [42]. These examples illustrate how certain features of MEMS, in this case their ability to operate in both an optical and electrochemical manner, can be leveraged for broad utility.

Microfabricated pressure sensors also have the potential for in vivo application. A capacitance-based pressure sensor can be microfabricated with a membrane that deforms according to pressure difference, causing a change in capacitance between the membrane and an electrode on the surface of the device. One such capacitance-based pressure sensor has been tested in vitro on a silastic tube made to mimic a 
pliable blood vessel [36]. This system could be implanted in small mammals to measure blood pressure during studies of hypertension and cardiovascular physiology. Another capacitance based pressure sensor has been fabricated for intraocular implantation in glaucoma patients [43].

A number of researchers are pursuing the use of hydrogels as components in MEMS and microfluidic sensing systems. The swelling rate of a hydrogel is inversely related to the size of the hydrogel [44]. The small size scale of MEMS, therefore, offers a unique opportunity to take advantage of the capabilities of responsive hydrogels in sensing and valving applications. Hydrogels that swell in response to changes in osmotic pressure [45], $\mathrm{pH}$ [46]-[49], or temperature or analyte concentration [50] could be quite useful for sensing applications in vivo. A MEMS-based, modified-hydrogel pressure sensor has been demonstrated as a wireless transducer for biosensing applications [51]. Biomimetic hydrogel valves have also been demonstrated in vitro that mimic the structure and function of venous valves [52], [53]. Electrically responsive hydrogels could also provide utility as components of MEMS-based sensors or drug delivery devices [54].

Issues of biocompatibility occur at the interface between device and tissue or blood, which means that the packaging of biosensors is essential for the success of any sensor design. An electrochemical sensor array was developed which fit inside a dual lumen catheter and could be monitored using telemetry [55], [56]. The array was designed for in vivo monitoring of blood $\mathrm{pH}$, carbon dioxide, and oxygen. $\mathrm{An}_{\mathrm{IrO}_{\mathrm{x}}}$ electrode was used for $\mathrm{pH}$ measurement and the gases had internal reference electrodes, as well as a working and reference electrode included in the catheter package.

Some biomedical sensors function at the surface of the body to replace lost sensory perception. One such application is retinal stimulation to compensate for photoreceptor degeneration in the back of the eye. A flexible silicon microstimulator controlled telemetrically by CMOS image sensors has been demonstrated [57], [58]. MEMS piezoresistive shear stress sensors have also been applied to the detection of shear stress at the interface between above-knee prostheses and the skin of the stump, to prevent tissue damage arising from excess shear that may go unnoticed by patients due to neuropathy near the site of amputation [59], [60]. These sensors may also be used with functional neuromuscular stimulation to assist in postsurgical evaluation of motor function or to help prevent diabetes-related foot ulcerations or pressure sores in wheelchair patients [61].

The ability to transduce physical and chemical stimuli to an electrical signal is a capability of MEMS sensors that would be difficult to achieve with polymeric systems. This multiple functionality of MEMS sensors may allow better integration of biomedical devices with the in vivo environment than could otherwise be achieved through existing technology.

\section{B. Stents}

An unusual area in which the application of microfabrication technology may offer improved device function is that of stents. Stents are one method by which the size of arteries can be increased in patients with heart disease and narrowing of the arteries, and stents are sometimes used to repair aneurysms [62]. Typically stents are fabricated from stainless steel. While coronary stenting has a lower restenosis rate (reblockage of the arteries) than balloon angioplasty alone, stents can increase the occurrence of intimal hyperplasia, one of the main histological components of restenosis, and cause higher incidence of in-stent restenosis (ISR) in certain groups of patients [63]. Important progress has recently been reported for drug-eluting stents as well as studies of stents coated with biodegradable polymers [64] as possible avenues to minimize ISR. The drugs of greatest interest include paclitaxel [65], sirolimus [66], and actinomycin-D [63]. Both the NIR Conformer (manufactured by Boston Scientific, Inc., TAXUS trials) and Penta (Achieve, Guidant, DELIVER trial) stents are coated with paclitaxel, while the Bx Velocity sirolimus-coated stent (manufactured by Cordis and Johnson \& Johnson) has shown promising results in clinical trials [67], [68]. Several different methods of loading stents with drugs are used, most commonly either applying a coating of pure drug, or a drug and polymer solution to the surface of the stent [63]. Newer methods include wrapping the stent with a polymer sheath in which the drug is embedded [69], coating the stent with a photopolymerizable gel in which the drug is immobilized [70], or fabricating drug-containing reservoirs into the struts of the stent [71]. Control over the rate of drug release from the stent may ultimately prove to be an extremely important factor in managing the efficacy of the stent for restenosis prevention. Although a number of companies are investigating drug-eluting stents, thus far the clinical results have not generally been as promising as expected.

Some researchers are, therefore, investigating the application of microfabrication technology to optimize the performance of stents. Stainless steel stents (BeStent, Medtronic, Inc.) have been coated with titanium-nitride-oxide alloys via physical vapor deposition in an effort to improve their biocompatibility. These coated stents exhibited lower fibrinogen binding and platelet adhesion in porcine coronary arteries over a period of six weeks [72]. Another approach is to use microfabricated structures to aid in the delivery of drugs from stents through arterial plaques. This plaque can be up to $200 \mu \mathrm{m}$ thick and is quite compressed. Silicon microprobes could be used to deliver therapeutic agents, such as those described above, to the arterial wall [73]. The microprobes can be fabricated by anisotropic (potassium hydroxide) etching of silicon using photolithographically patterned silicon dioxide as an etch mask. Microprobes having a height of $140 \mu \mathrm{m}$ were found to penetrate the internal elastic lamina and media in atherosclerotic iliac arteries of rabbits when applied with a pressure of approximately $67000 \mathrm{~Pa}(500 \mathrm{~mm} \mathrm{Hg})$. These devices can penetrate through the various layers of the vessel wall, but the challenge of fabricating a three-dimensional, cylindrical structure for use as a stent may require the development of new nonplanar microfabrication techniques. This approach nevertheless provides an example of a novel application of microfabrication technology that makes use 
of properties unique to MEMS, specifically the biologically relevant feature size and precision fabrication techniques.

\section{Immunoisolation Devices}

One area in which MEMS technology may offer significant improvement over the current state of the art is that of immunoisolation. Traditionally, polymer-based capsules are used for implantation of cells [74] in an attempt to prevent immunorejection. Semipermeable immunoisolation capsules are used, for example, to isolate implanted islet cells from the surrounding biological environment, while allowing the cells to remain viable and secrete insulin for treatment of diabetes. Polymer-based capsules suffer from several disadvantages, including inadequate mechanical strength and a broad pore size distribution. These factors can cause mechanical failure of the capsule and immunorejection due to diffusion of antibodies (usually immunoglobulin $\mathrm{G}$ or immunoglobulin $\mathrm{M}$ ) and complement components through the membrane. Microfabricated silicon capsules, however, offer the advantages of reproducible small features (due to the precision and reproducibility of the microfabrication processes) and greater mechanical strength (due to the strength of the silicon and other MEMS materials compared to polymeric materials). Nanoporous silicon membranes have been fabricated using a combination of surface and bulk micromachining. A cell-containing microcapsule can be formed by bonding two of these microfabricated membranes together. Insulinoma and pancreatic islet cell containing microcapsules with 18-nm pores have shown viability, immunoprotection, and insulin secretion in response to glucose stimulus after implantation in vivo for eight days [75]-[77]. Similar microcapsules without cells were implanted in male Lewis rats for a period of two weeks. Capsules that were sutured to the abdominal wall were surrounded by a dense fibrous capsule at the conclusion of the study, while capsules that were implanted in the omental pouch had no fibrotic growth, and were surrounded by a vascular network [78]. The improved immunoisolation provided by microporous siliconbased structures may allow for allo- and xeno-transplantation of tissues such as pancreatic islets, offering new hope for diabetic and transplant patients.

\section{Drug Delivery Systems}

An area of rapidly increasing interest is the use of microfabricated devices and structures for drug delivery. The digital capabilities and short response times of MEMS make them attractive for drug delivery applications in which triggered pulsatile drug release is desired. Further, the reproducibility of the microfabrication processes may minimize batch-to-batch variation of the devices in comparison to current biomedical and drug delivery implants, which is highly desirable from the regulatory and quality control viewpoints. Incorporation of sensing components, such as the hydrogels discussed earlier, may allow for the achievement of a "smart" or responsive MEMS drug delivery system.

The use of MEMS for drug delivery requires the existence of a drug depot or supply within or on the device. A number of approaches are being pursued in an effort to devise new reservoir-containing structures fabricated from traditional MEMS materials such as silicon as well as polymeric materials.

1) Microparticles: One straightforward approach to realize a microfabricated drug reservoir is the fabrication of silicon microparticles that contain an internal reservoir loaded with drug [79], [80]. Standard microfabrication techniques (photolithography and wet or dry etching) are used to pattern wells ranging in size from 25 to $100 \mu \mathrm{m}$ inside silicon squares ranging from 80 to $150 \mu \mathrm{m}$ in size. The reservoirs can be filled using a microinjector attached to a micromanipulator, and the devices are small enough to be injected or ingested. Devices injected intravenously could have a slow dissolving cap, fabricated from gelatin or starch, for example, over each reservoir to prevent burst release of the drug upon injection. Grafting of fibroblast growth factor (FGF) to the surface of the device could provide a high-affinity ligand for proliferating vascular endothelial cells, which are often found in tumors, and enable the microparticles to target delivery of their drug load to cancerous cells [81]. Oral drug delivery could be achieved from these devices by ingestion of an enteric capsule that contains the drug-loaded microparticles. Upon dissolution of the capsule in the gastrointestinal tract, release of the drug could be triggered by the binding of a surface-functionalized molecule to cells in the digestive tract. Lectin-functionalized microdevices, for example, have shown increased adhesion to Caco-2 cells in an in vitro study that investigated the feasibility of using these devices for drug delivery [80].

2) Silicon Microreservoir Devices for Drug Delivery: Another microfabrication approach for drug delivery is a silicon-based MEMS device consisting of an array of microreservoirs [82]. Each dosage of drug is contained in a microreservoir that is covered with a gold membrane. Application of an anodic voltage to the membrane of interest causes electrochemical dissolution of the membrane in the presence of chloride ions. This causes the membrane to weaken and rupture, allowing the drug within the reservoir to dissolve and diffuse into the surrounding tissue. This device allows the release of potent substances in a "digital" manner, such that small pulses of drug can be combined to produce a complex release profile or one with tight dosage control [83]. Each microreservoir can be individually filled, so multiple substances can be delivered from a single MEMS device. This device contains no moving parts, and when packaged with a power source and programmable clock would be approximately the size and weight of a pacemaker. A simpler version of the device could be an ingestable platform for a few releases at timed intervals along the gastrointestinal tract.

Release of fluorescent dye and radiolabeled compounds has been demonstrated from these microreservoir devices in vitro in saline solution and serum [82], [84]. Approximately $1 \mathrm{~h}$ was required for $75 \%$ of the contents to be released from opened reservoirs. The release rate exhibited a sharp pulse with a tail that tapered off so that a small amount of release was detected 24 to $48 \mathrm{~h}$ after activation. It is expected 
that the release kinetics will depend strongly on the compound's dissolution and diffusion behavior. Release of radiolabeled drugs from the microreservoir devices has also been demonstrated in vivo [85], and further studies are ongoing to demonstrate multiple pulses of drug release from the devices in vivo.

The principle of the drug release from this microreservoir device is based on the electrochemical dissolution of the anode gold membranes. Understanding the mechanism of this process is important to achieve reliable device performance. In situ observation of chemical release tests has provided evidence that there is a close interaction between the electrochemical corrosion and the mechanical integrity of the gold membranes [86]. Therefore, characterizing the mechanical integrity of the gold membranes is paramount in the study of device reliability. The mechanical properties of the gold membranes on these microreservoir devices have been investigated using a bulge test [87]. In this test, uniform differential pressure is applied from underneath each individual gold membrane, and measurement of the pressure versus deflection relation allows extraction of the membrane mechanical properties, such as elastic modulus and residual stress. A series of tests in which gold membranes were subjected to applied voltages for varying amounts of time confirmed that the electrochemical corrosion induces a gradual loss of the mechanical integrity of the gold membranes, which eventually mechanically rupture and open. Knowledge from these studies can be used to optimize the design of the gold membranes in order to achieve more reliable and reproducible membrane opening behavior and, hence, better control over the release of drugs from these devices.

A unique aspect of this MEMS drug delivery system is that it offers the ability to separate the formulation that controls drug stability from the formulation or mechanism that controls drug release. This is in contrast to many of the polymeric drug delivery systems that have been developed, which typically consist of a physical mixture of the drug to be released and a biodegradable polymer. Changing the drug loading in such a polymeric system, for example, may change the release kinetics of the drug from the device. Additionally, a great amount of effort in the pharmaceutical industry is targeted toward ensuring that the drug formulation is optimized to prolong the stability of the drug, but formulation optimization may be restricted by the fact that the polymer matrix must necessarily be part of that formulation. The mechanism or formulation that controls the release of drug from the silicon microreservoir devices described here, in contrast, is simply the gold membranes that seal the reservoirs. It is expected that for most drugs, the formulations within the reservoirs can be changed without causing any effects on the gold membranes or release mechanism.

Another important reliability issue for this microreservoir device is its long-term stability, which is currently being investigated through a long-term implantation study. This study will test the long-term stability of not only the gold membranes, but also all other materials involved on this device. There have been concerns about the long-term stability of the silicon oxide passivation layer on the device, which could be replaced by more stable dielectric materials such as silicon carbide or oxycarbide, if necessary. The short-term biocompatibility of the component materials of this device has been studied and will be discussed in Section IV-A.

3) Polymer Microreservoir Devices: Most polymer drug delivery systems currently in commercial development or research are based on the depot principle. These systems often are composed of a physical mixture of the drug of interest and a polymer, as was described above. Delivery of the drug is typically achieved by diffusion of the drug through the polymer substrate or pores in the implant, or by degradation of the polymer and subsequent release of the drug. However, other researchers are exploring the use of nontraditional MEMS fabrication techniques and materials that could be used to form microwell- or microreservoir-based drug delivery devices. For example, microwells of varying sizes (as small as $\sim 3 \mathrm{fL} /$ well) have been fabricated by micromolding of poly (dimethylsiloxane) (PDMS) on a photoresist-coated silicon wafer that is photolithographically patterned [88]. These microwells can be filled with solutions by using the principle of discontinuous dewetting. Either the array can be immersed in a bulk solution and then removed in order to fill the reservoirs or the liquid can be spread over the surface of the array to fill the wells and then allowed to drain off the array due to gravity. This method allows uniform filling of the wells with extremely small volumes, which might be difficult to achieve using other more standard filling methods such as microinjection, inkjet printing, micropipetting, or using a picospritzer. Other investigators have fabricated millimeter-sized reservoirs in micromolded polycaprolactone and sealed droplets of water inside the reservoirs with a gold membrane that covers the reservoirs [89]. The use of ultraviolet laser micromachining (ablation) has been explored for micropatterning of biodegradable polymer substrates [90]. Grooves and holes were patterned in multilayer poly (D-lactic acid) and poly (vinyl alcohol) (PVA) films and single-layer PVA films, respectively. The grooved structures are designed to provide guidance to neurons (peripheral nerve regeneration), while the PVA films with 5- to $10-\mu \mathrm{m}$ holes could be used for ultrafiltration applications. This technique of laser ablation could also be used for micromachining of drug reservoirs in polymeric devices. These pioneering efforts may ultimately lead the way toward MEMS that incorporate more biocompatible and biodegradable materials, combining the advantages of microfabrication technology, such as small feature size and device reproducibility, with the greater biocompatibility or biodegradability of various polymers.

\section{INJECTABLE MEMS}

Some researchers are investigating the applicability of injectable MEMS for in vivo use. This research has focused on two main areas, the first being microneedles for drug delivery and other applications, and the second being injectable micromodules for neuromuscular stimulation or sensing applications. 


\section{A. Microneedles}

The development of microneedles has taken advantage of the small feature size that can be achieved through microfabrication processes, mainly for noninvasive drug delivery applications. Several microfabricated microneedle schemes have been proposed, including microhypodermic needles, disposable arrays of microneedles for use with a syringe, and solid needles to increase skin permeability for use with a transdermal patch [91]-[93]. Microneedles can be used to deliver compounds to cells in culture or into localized regions of tissue inside the body, and can be fabricated from silicon, glass (silicon dioxide), and metal. Microneedles can deliver drugs transdermally without pain because they do not penetrate to skin layers that contain nerves, but they do penetrate far enough for the therapeutic compounds to enter systemic circulation [94].

Microneedles produced an order of magnitude increase in cadaver skin permeability to model small molecules such as calcein [93]. The delivery of macromolecules such as oligodeoxynucleotides and ovalbumin has been demonstrated using stainless steel microprojection arrays (Macroflux, manufactured by Alza) [95], [96]. Comparable anti-ovalbumin antibody titers were obtained for dosages of 20 and $80 \mathrm{mg}$ whether administered by microprojection array or the more traditional routes of intradermal, subcutaneous, or intramuscular injection.

\section{B. Injectable Micromodules}

Injectable micromodules are a new class of implants that are used to deliver electronic devices such as neuromuscular stimulators to the human body [97]. In this application, the ability to fabricate electronic devices with small feature sizes has allowed a high degree of functionality to be condensed into a very small device. Current micromodule systems are small enough to be implanted by percutaneous injection through large-gauge hypodermic needles, eliminating the need for surgical implantation. Moreover, each of the 256 microstimulators in the system could be individually directed to produce electrical stimulation, offering a wide range of rehabilitative and therapeutic applications.

The principle of injectable micromodules is basically the same as that of the commercially available radio frequency identification (RFID) devices. The RFID tag is a subminiature glass capsule containing a solenoidal coil and an integrated circuit, which form a transcutaneous inductive link to power and communicate with the device [98]. Advances in monolithic electronic design and MEMS packaging technologies led to expansion of RFID technology to the medical field to create injectable micromodule systems. Current development is aimed at more complex functions such as bioelectric/goniometric/temperature sensing, and functional electrical stimulation [97], [99], [100].

\section{BIOCOMPATIBILITY AND PRESERVATION OF TISSUE FUNCTION}

Thus far we have focused on how the application of microfabrication technology can improve the integration and function of implantable devices. Understanding the interaction between the implanted MEMS materials and the local cellular environment, and assessment of the immune response, are critical, however, for optimizing the performance of MEMS in vivo. In this section we review the current understanding of the biocompatibility of some common materials used in MEMS fabrication, examine strategies currently being used to improve the biocompatibility of MEMS, and briefly discuss some novel applications of microfabrication technology to actively control and direct cell attachment and growth.

\section{A. MEMS Material Biocompatibility}

Biocompatibility testing of implant materials is becoming increasingly complex, and MEMS devices have unique biocompatibility issues. The biocompatibility requirements vary considerably depending on the device function and design; biocompatibility is defined by The Williams Dictionary of Biomaterials as "the ability of a material to perform with an appropriate host response in a specific application" [101]. The performance of sensors (glucose, $\mathrm{pH}$, etc.), for example, is limited by biofouling and isolation of the sensor surface. However, neural electrodes must remain in intimate contact with the neurons that they are stimulating or recording. The ISO 10993 standards outline minimum tests of material characterization, toxicity, and biodegradation that may be augmented depending on actual device usage.

Biocompatibility can be assessed using several types of tests. In vitro assays include leaching of material, corrosion testing, protein adsorption testing, and cell culturing on material samples. In vivo biocompatibility assays typically involve the implantation of material or a device at the eventual site of use (intramuscular, subcutaneous, etc.). In vitro assays are easier to perform and provide more quantitative results, but in vivo assays are more relevant and can capture systemic effects. The local and systemic responses, such as fibrous capsule formation, lymphocyte response, or accumulation of particulates in lymph nodes, are evaluated over days, weeks, or months. In vivo tests can also exhibit variation due to implant shape, surface texture, and size. Large implants, sharp edges, and implants that rub against tissue will induce a greater reaction in the host tissue. The variability of test design mirrors the variability of device function.

The biocompatibility of MEMS materials was not addressed until recently because these materials were packaged or encapsulated away from direct contact with tissue and fluids; biocompatibility is a surface-mediated property, and the biocompatibility of a device depends only on those materials in contact with tissue. The biocompatibility of silicon and other MEMS materials has become much more important with the advent of implantable MEMS devices that interact directly with the body. The biocompatibility of some MEMS electrode materials has been studied, however, because of their use in other devices such as pacemaker electrodes and dental implants.

Silicon substrates are the basis for most MEMS devices, and silicon compounds commonly enable device function. 
A comprehensive evaluation of silicon materials was completed by Kotzar et al., who performed the baseline ISO 10993 tests on single crystal silicon, polycrystalline silicon, silicon dioxide, silicon nitride, single-crystal silicon carbide, titanium, and the photo epoxy SU-8 [102]. This basic information will be valuable to guide future device design and materials selection, although slight variations in processing and composition may change the results of biocompatibility tests. They found that only silicon nitride and SU-8 leached detectable nonvolatile residues in aqueous physiochemical tests, and only SU-8 leached detectable nonvolatile residues in isopropyl alcohol. None of the materials were found to be cytotoxic in vitro using mouse fibroblasts. All seven materials were classified as nonirritants based on 1- and 12-week rabbit muscle implantations. Based on these results, these researchers concluded that there were few concerns about using any of these materials for implanted devices.

The biocompatibility of MEMS materials for the silicon microreservoir drug delivery device (see Section II-D2) has been studied using a cage system that was previously used for polymers [103]. Material samples were placed within a stainless steel wire mesh cage and implanted subcutaneously in rats. The lymphocyte concentration and adherent macrophages and foreign body giant cells (FBCG) were measured out to 21 days to characterize the acute and chronic biocompatibility. The advantage of this technique is that it is both in vivo and quantitative. The results indicated that silicon, silicon nitride, silicon dioxide, gold, and SU-8 were biocompatible, and all but silicon and SU-8 had reduced biofouling. In a similar study, silicon nitride was implanted in Teflon containers in rabbits [104]. Silicon nitride was determined to be biocompatible under these conditions and was suitable for long-term implantation of pH-ISFET sensors.

Silicon microshafts and microneedles have been tested for their suitability as neural implants. Silicon microshafts have been implanted in rabbit brains for 6 mo and the neuron density around the shaft analyzed [105]. It was determined that the geometry of the shaft is highly important, and that recording and stimulating sites should only be placed along the sides of the shaft and not near the shaft tip. Shafts must also be well sharpened and have sufficiently small tip angles. The tissue response to implanted silicon shafts has also been studied up to 12 weeks in rats [106]. A sheath of cells was found to surround the shafts, becoming highly compacted and continuous by six weeks, and isolating the shaft from the brain. The biocompatibility of silicon-based microelectrode arrays was evaluated in vitro using brain slice cultures [107]. Silicon microelectrodes with silicon nitride and platinum-coated tips were found to support cell cultures similarly to conventional semiporous membranes. These microelectrode arrays may be used in vitro to study defined neural networks and perform neurotoxicological screening.

The biocompatibility of silicon membranes with well-controlled pore sizes to encapsulate pancreatic islet cells has been studied [75], [108]. These biocapsules allow nutrients and small molecules to pass freely through the membranes while isolating transplanted cells from rejection by the patient's immune system. Desai et al. found that silicon biocapsules provided islet cells with immunoprotection for 30 days in mice. The islet cells retained their ability to secrete insulin throughout the implantation.

Porous silicon, when implanted in rat abdominal walls up to 12 weeks, was found to have the same cell densities of macrophages, total cells, and necrotic cells as porous titanium and smooth planar silicon and titanium [109]. However, both of the porous surfaces were found to evoke significantly thinner fibrous capsules with fewer cells at the implant interface at 12 weeks. Porous silicon was more biocompatible than planar silicon, and comparable to porous titanium, a commonly used orthopedic implant material. The porosity and pore size of silicon has been found to affect the bioactivity of silicon [110]-[112]. Low-porosity microporous films induced hydroxyapatite growth in vitro; high-porosity mesoporous films exhibited substantial dissolution in vitro, while planar silicon was inert in the same medium. These characteristics may be used to aid MEMS implant design to select bioactivity or bioinertia depending on device function.

The electrode materials for implantable MEMS devices are typically gold, platinum, or titanium. The noble metals have a long history of successful use in dentistry, and more recently as electrodes for pacemakers, while titanium is successfully used for many orthopedic implants. Higher noble metal content in dental alloys has been shown to increase biocompatibility [113]-[115]. Several studies of the biocompatibility of silicon also address the biocompatibility of one or more electrode material [102], [103], [107], [109]. A study of electrodes for an electrochemical sensor found that both gold and activated carbon electrodes were biocompatible and successful reference electrodes for four years of implantation in dogs [116].

The operation of the silicon microreservoir drug delivery device discussed in Section II-D2 includes the electrochemical dissolution of metallic gold to soluble gold chloride. Gold-coated pacemaker electrodes that eluted gold chloride were found to have superior acute and chronic pacing performance with reduced inflammation and scar [117]. Gold salts have been used for the treatment of rheumatoid arthritis because of their anti-inflammatory characteristics. Macroscopic gold voltammetry devices have been implanted subcutaneously in rats and the inflammatory response analyzed using the cage implant system [118]. Voltage application and gold dissolution were found to induce an acute inflammatory response equivalent in magnitude to the initial implantation, but which was resolved within $72 \mathrm{~h}$. A follow-up study of repeated activation of microscale gold membranes is currently being conducted.

\section{B. Surface Modification}

Although biocompatibility and tissue function preservation are of vital importance, the ultimate utility of many implantable MEMS devices may be limited by another device-biological environment issue-namely, biofouling. The adsorption of biomolecules (peptides and proteins) 
followed by cells frequently leads to device fouling and failure. Major research efforts are dedicated toward developing methods to substantially reduce the phenomenon and produce devices that do not promote biofouling, yet retain their biocompatibility. This effort often takes the form of surface chemical modification of silicon, silicon oxide, or metal surfaces on the device. Little of this work, however, has been conducted on functional drug delivery MEMS devices. Therefore, the results described here use modification methods on materials that are often incorporated into MEMS devices. Several recent reviews cover general issues in bioadhesion and protein adsorption without specifically addressing MEMS devices [119], [120]. Chemical modification to reduce biofouling falls into one of two general methods. The first method uses surface immobilized polymers that reduce adsorption of biological materials. The second method relies on the self-assembly [121] process to passivate the MEMS device surface. Specific examples, methods of preparation and characterization, and representative results for these two methods are described below.

1) Surface Immobilized Polymers: Many of the polymer-based modification methods rely on attachment of poly (ethylene glycol) (PEG) or its analogues to the surface [122]-[124]. The ability of these materials to inhibit protein adsorption and therefore reduce biofouling has been known for decades [125]. Other related polymers are also being explored to minimize protein adsorption. Recent examples include tetraglyme $\left.\left(\mathrm{CH}_{3} \mathrm{O}\left(\mathrm{CH}_{2} \mathrm{CH}_{2} \mathrm{O}\right)_{4}\right) \mathrm{CH}_{3}\right)$ [126] and copolymers of ethylene glycol such as poly (acrylamide-co-ethylene glycol) [127] and poly (L-lysine) grafted with PEG side chains [128]. The development of copolymers containing ethylene glycol may enable more precise tailoring of materials surface properties.

Numerous methods for the immobilization of the polymer onto silicon, silicon oxide, metal, or metal oxide surfaces have been developed. Grafting by way of photoinduced polymerization or chemical surface attachment to silicon oxide are two common preparative methods [122], [124], [127]. Vapor deposition techniques [122] and gas-phase plasma polymerization [123] also yield polymer-coated surfaces. The grafting of PEG onto cationic polymer chains such as poly (L-lysine) enables attachment to negatively charged surfaces (silica and some metal oxides) via simple electrostatic interactions [128]. Films are characterized through a variety of surface analytical methods such as contact angle goniometry, X-ray photoelectron spectroscopy, ellipsometry, surface plasmon resonance spectroscopy, probe microscopy, and secondary ion mass spectrometry. The polymer film formation dictates many physicochemical properties of the interface. In general, however, the polymer film thickness falls in the 2- to 20-nm range. Additionally, the modified surfaces are usually hydrophilic regardless of the nature of the underlying substrate.

The utility of the polymer-modified surface against biofouling is probed by incubation in a biological medium. The medium contains either a protein (e.g., albumin, fibrinogen, or Immunoglobulin G) or a cell line (fibroblast, HeLa, or endothelial). Following incubation, researchers measure the amount of adherent materials and compare to unmodified controls. In all studies, substantial reduction of adherent protein/cells is seen. A study of PEG on silicon surfaces [122] is of particular interest to those in the MEMS field. The researchers fabricated nanostructured thin $(\sim 2.0 \mathrm{~nm})$ films of PEG on silicon substrates. The nanostructured nature of the film may enable retention of MEMS device functionality by minimizing the inhibition of molecular transport to or from the device. The system reduces by approximately a factor of ten the amount of bovine serum albumin that adheres to unmodified silicon in devices. Hanein et al. [123] fabricate micromachined PEG films using standard photolithographic techniques. The technique shows promise due to its application to myriad surfaces, including silicon, silicon oxide, silicon nitride, gold, and platinum. Importantly for some MEMS applications, the conductivity of the metal substrate is retained.

2) Self-Assembled Monolayers: Certain types of self-assembled monolayers (SAM) have been known for more than a decade to passivate surfaces against protein and cellular adsorption [129]. These monolayers spontaneously form dense overlayers on numerous surfaces relevant to MEMS. The first type of SAM shown to reduce biofouling is an oligo (ethylene glycol) terminated alkanethiol moiety. A number of other SAMs resistant to adsorption have been identified since the initial studies in which two to six ethylene glycol groups sufficiently reduced protein and cellular adsorption. A wide range of terminally functionalized alkanethiols has been found to be protein resistant [130]. Useful functional groups include some amides, amines, ethers, nitriles, and sugars. The breadth of chemical groups allows some tailoring of surface properties. Other SAMs of note for MEMS devices are alkoxysilyl [124] and trichlorosilyl terminated PEG [131], and PEG terminated trialkoxysilanes [132] and trichlorosilanes [120]. These species react with oxide surfaces, particularly silicon oxide, to yield robust protein-resistant interfaces. A final system related to the SAM-modified surfaces bears note. Researchers have suppressed the protein adsorption on silicon surfaces by transferring phospholipid-based Langmuir-Blodgett monolayers to device surfaces [133].

The formation method for both the thiol on metal and silane on oxide systems is very simple. The thiols form a strong sulfide-metal bond spontaneously from ethanolic solutions. The trichlorosilane and trialkoxysilane systems also produce a strong interfacial bond, in this case a $\mathrm{Si}-\mathrm{O}-\mathrm{Si}$ bridge, between substrate and adsorbate. The latter reaction is catalyzed in solution using an amine. Although immersion of the MEMS device into a solution containing the target molecule produces useful layers, methods for patterning of the layers allow for more flexibility. The SAM is generally patterned either with standard photolithographic techniques or with stamping of monolayer molecules using a patterned mold [119], although some patterning of SAMs had been achieved by using computer-controlled laser ablation [134]. Patterning the SAM allows the electrochemical properties of the device to be retained in specific regions. This is particularly vital for MEMS devices relying on electrochemical 
sensing or release [82], [135]. The resultant films formed by self-assembly have several properties in common. First, similar to the polymer-modified surfaces, the films are generally hydrophilic as measured by contact angle goniometry. Second, the SAM method allows excellent control over film thickness and surface density.

Results from SAM-modified MEMS indicate a substantial reduction in adsorption of protein and cells, similar to the results obtained with polymer surface modification. Proteins (fibrinogen, albumin, and pyruvate kinase) and cell lines (glial and bovine capillary endothelial) show markedly decreased adhesion on SAM-modified gold, silicon, and silicon oxide surfaces. One example of a SAM-modified device, though not specifically a MEMS system used in vivo, is the work of Schoenfisch et al. [117]. The researchers employ self-assembled monolayers to cardiac pacemaker electrodes and observe improved device biocompatibility and behavior over an 80-day trial.

Most of the research in the areas of surface immobilized polymers and self-assembled monolayers is on model surfaces in vitro, although both of these methods for MEMS device modification are advancing rapidly. These surface modification methods will be tested in vivo on functional MEMS devices in the near future.

\section{MEMS Technology for Tissue Engineering}

Another area of burgeoning interest in the field of MEMS is to use microfabrication technology and chemical modification to investigate and direct cell growth (see [136] for a brief review). In contrast to the use of chemical modification to prevent biofouling (see Section IV-B), chemical functionalization can also be combined with microfabricated and microtextured surfaces to provide a new method by which to control cell attachment and differentiation in vitro, as well as device integration with living tissue in vivo. These techniques may ultimately lead the way toward functional MEMS that operate in conjunction with living tissue.

Several groups have studied the effect of topography and microtexture on the attachment of different types of cells. The preferential attachment of osteoprogenitor cells has been investigated on Mylar films containing grooves of varying spacing, width, and depth [137]. The grooves are carved into the surface of the Mylar film using a $\mathrm{KrF}$ excimer laser beam that is coupled with a metal photomask that does not touch the surface of the polymer film. This procedure provides an image compression ratio of ten, and allows groove widths ranging from 3 to $30 \mu \mathrm{m}$, and groove depths from 1 to $10 \mu \mathrm{m}$. Osteoprogenitor cells showed an increase in adhesion to surfaces that had a decreasing width and depth of microgrooves. Another example of the application of microfabrication techniques for investigating cell adhesion can be found in a study that examined the attachment of astroglial cells to smooth silicon and silicon pillars and wells of varying geometries [138]. Photolithography, plasma etching, and $\mathrm{HF}$ etching were used to fabricate silicon dice having alternating smooth-etched silicon areas and arrays of pillars and wells. Each subdie contains pillars of a specific width (between 0.5 and $2.0 \mu \mathrm{m}$ ) and interpillar gap (between 0.5 and $5.0 \mu \mathrm{m}$ ). The subdice with an interpillar gap of $0.5 \mu \mathrm{m}$ contained wells instead of pillars. It was found that $70 \%$ of the astroglial cells preferentially attached to the stripes of pillars versus the smooth silicon, but only $40 \%$ of the cells preferentially attached to the etched wells versus the smooth silicon. Additionally, the degree of cellular spreading was found to increase as the pillar width and interpillar spacing were increased, and the cells appeared to grow on the tops of the pillars, and not in between them. These results indicate that patterned topography could have valuable applicability for neural prosthetics, as greater integration of the host tissue could be achieved by micropatterning the surfaces of MEMS devices.

The dependence of monocyte cell aspect ratio and phagocytic ability as a function of electrical heterogeneity of polystyrene surfaces has also been investigated [139]. Microfabricated interdigitated gold or titanium electrodes were patterned on a quartz substrate and electrically isolated by a layer of tissue culture grade polystyrene. A rectified direct current power source was used to externally address the electrodes, and the applied voltage ranged from \pm 30 to $\pm 75 \mathrm{~V}$. Cells cultured on the electrically heterogeneous (electrode containing) surfaces showed greater cell spreading (change in aspect ratio) and greater phagocytosis of fluorescein-labeled human immunoglobulin $\mathrm{G}$ opsonized zymosan particles compared to cells on the electrically homogeneous polystyrene surfaces, especially for cells cultured on the surfaces having the highest charge densities ( \pm 45 to $\pm 75 \mathrm{~V}$ ). One possible application of these results might be to passively electrostimulate cells for enhanced phagocytosis at a wound or infection site, for example, to prevent infection of chronic indwelling catheters.

Other researchers are utilizing a combination of micropatterned and chemically functionalized surfaces to control cell attachment and behavior. Control over murine connective tissue cell adhesion has been achieved by selective functionalization of ridges and grooves on microfabricated polymer surfaces with fibronectin (cell adhesive) and hydrophobic organosilanes (cell repulsive) [139]. Photolithographically patterned silicone elastomers have also been used to culture cardiac myocytes in vitro [140]. Five- to $10-\mu \mathrm{m}$-wide grooves on the surface of the silicone allow directional growth of the cells, while functionalization of the silicone surface with an RGD (Arg-Gly-Asp) peptide sequence enhanced the adhesion of the myocytes to the surface. Cardiac myocytes have also shown enhanced cellular attachment and orientation, as well as a cellular morphology more similar to that seen in vivo, when grown on silicone microtextured surfaces (fabricated from photolithographically defined silicon wafers) with 5- $\mu$ m-tall pegs as compared to normal cell culture dishes [141].

Finally, other researchers are using MEMS or microfabricated structures as scaffolds for tissue engineering. Micromolding in capillaries (MIMIC) has been used to fabricate polyurethane (PU) structures that could be used as scaffolds for bone [142]. Three-dimensional structures were fabricated by stacking several single PU microchannel 
layers with thin layers of PU precursor in between to act as glue. The authors envision fabrication of different trabecular bone scaffolds (plate-like, hybrid, and rod-like) by varying the microchannel structure. These scaffolds could be seeded with cells for implantation. Others are investigating the use of silicon scaffolds for hepatocyte culture [143]. Deep reactive ion etching (DRIE) is used to form micropores in a $230-\mu \mathrm{m}$-thick boron-doped silicon wafer. This wafer is sandwiched between two coregistered array plates, seeded with primary rat hepatocytes, and contained in a reactor housing. Tissue culture medium is perfused through the reactor. Reactors that were seeded with hepatocyte spheroids (preaggregated cells), showed the formation of tissue-like structures that maintained their structure and viability for up to the two weeks of the study. This represents an improvement over typical in vitro cell culture conditions, under which hepatocytes rapidly lose their liver-specific functions. Finally, another notable endeavor is the use of silicon micromachining and polymer replica molding to produce scaffolds for vascular tissue [144]. In vitro engineering of complex tissues and organs is often limited by the lack of an intrinsic blood supply. Tissue thicknesses of greater than 1-2 $\mathrm{mm}$ are sufficient to cause significant cell death, as oxygen from the surrounding tissue culture medium cannot diffuse far enough into the tissue to support cells in the interior of the tissue construct. The use of microfabrication techniques to engineer a microvasculature for organs and tissues requiring a blood supply is one possible route to address this problem. Standard microfabrication, photolithography, and plasma etching techniques can be used to pattern a vasculature pattern developed through evolutionary fluid dynamic design into a silicon wafer. Replica molding can then be used to create a PDMS or poly (lactic-co-glycolic acid) (PLGA) microfluidic network. Two microfluidic sheets can be bonded together to form rounded channels, or a flat sheet can be bonded onto the surface of one microfluidic sheet. Microfluidic networks fabricated in this manner that were seeded with endothelial cells achieved confluence over most surfaces, without the occurrence of occlusion or contamination, over a span of four weeks.

These are but a few of the examples in which researchers are exploiting microfabrication techniques to understand the manner in which cells grow and to apply that knowledge for greater device functionality and integration with living tissue.

\section{ACTUATION SYSTEMS}

Much of the current MEMS research focuses on addressing a particular detail or aspect unique to specific problems or applications, such as the fabrication of a certain feature or the interaction of silicon with a certain type of cell. In this section we present a broader perspective of the application of MEMS for actuation of certain systems within the body. In contrast to MEMS for sensor or drug delivery applications, MEMS for actuation would not only allow information flow in two directions (sensation as well as stimulation, whether it be electrical or chemical), but would function in a synergistic manner with the body's own systems through the application of a potent stimulus at the critical time. A prime example of this type of system is the pacemaker, which provides a small stimulus at a critical time in order to actuate the cardiac system. Other applications that use drug delivery or chemical stimuli for actuation of the body's systems could also be envisioned.

\section{A. Pacemakers and Cardiology Devices}

The cardiac pacemaker was the first electronic device ever surgically implanted inside a human and is a demonstration of the success that can be achieved through the collaboration of the medical and engineering fields to solve medical problems. It is one of the few examples of widely used implantable devices that can be considered truly biologically integrated, and which has addressed the issues of device function, reliability, biocompatibility, sensing, and response to biological feedback. In light of our consideration of the potential for implantable MEMS, perhaps the most important aspect of the cardiac pacemaker is that it functions as an actuator or regulator for patients with cardiac arrhythmias, and is capable of restarting or correcting the beating of the heart. In this sense, the pacemaker works in tandem with the body's own cardiac system, interacting physically and electrically with the tissue of the body to correct malfunctions.

There have been many technological advances and rapid clinical progress during the past 40 years. Indications for permanent pacemakers have been greatly expanded to address a wide variety of specific cardiac arrhythmic problems, such as hypertrophic obstructive cardiomyopathy, dilated cardiomyopathy, and atrial fibrillation [145]. On the other hand, the introduction of microprocessors and miniaturization technologies has transformed the pacemakers from bulky, single-chamber, asynchronous (fixed rate) units to small, multiprogrammable, dual chamber, rate adaptive devices with diagnostic functions.

The obvious advantages of rate adaptive over fixed rate pacing have driven great interest in the development and implementation of rate adaptive pacemakers. The key technology in this development is the incorporation of one or multiple special sensors that can measure physiological signals so that pacing can be adjusted to match the cardiac output to the metabolic need. A sensor for rate adaptive pacing would ideally closely mimic the response of the sinus node with quick response to the different levels of exercise [146], [147]. Many sensors have been investigated, but none of them truly meets this goal. Accelerometer-based activity sensors (using piezoelectric crystals) are the most popular sensors used today [148]. There are other sensors based on minute ventilation, Q-T interval, oxygen saturation, central venous temperature, rate of rise of ventricular pressure $(\mathrm{dP} / \mathrm{dt})$, preejection interval (PEI), peak endocardial acceleration (PEA), and intracardiac impedance [149], [150]. Combinations of sensors have also been investigated. The combination of an activity sensor with a minute ventilation sensor, for example, has been shown to provide more physiological response to exercise [151]. 
Automaticity is another area of intense research interest in pacemaker technology with the ultimate goal of a "smart" pacemaker that incorporates multiple functions and can achieve optimal treatment and diagnosis for patients with specific indications [152], [153]. Several automatic algorithms have been implemented in pacemaker therapy for automatic capture detection, sensing detection, impedance measurement, and longevity estimation [149], [154]. New control algorithms based on fuzzy logic are being investigated for rate adaptive pacing [155]. A real-time Linux operating system has also been developed for this purpose [156]. The pacemaker diagnosis is becoming ever important and sophisticated to monitor the function of the device and help evaluate patient-triggered events during follow-up. This increased diagnostic capability is facilitated through the continuing innovation of programming and telemetry techniques, and the incorporation of random access memory (RAM) to store data and electrograms [157].

While the functionality of pacemakers is becoming increasingly more complex, their size is becoming progressively smaller. Next-generation pacemakers will continue to benefit from advances in miniaturization technologies to use smaller leads and connectors with improved reliability, smaller integrated circuits with a higher degree of integration, and smaller memory with greater capacity. Other aspects of pacemaker technology, such as packaging and power sources, are also being actively pursued [158]. The continuing incorporation of new features and refinement of device functions hold promises for implanted pacemakers to eventually become integrated cardiac rhythm management systems.

\section{B. Actuation Systems}

Although MEMS and electronic implants have long been associated with the cardiac and nervous systems due to their electrical nature, a large untapped potential may lie in the area of actuating systems within the body such as the nervous or endocrine system. Although historically these two systems were regarded as independent and having different functions, new research suggests that they may act together, albeit on different time scales, to affect a wide range of physiological processes. These systems control a variety of processes within the body, as exemplified by the role of molecules such as leptin and melatonin, which have been the subjects of increasingly intense scientific research and public interest over the past few years. Leptin, for example, seems to play a role in obesity and puberty, and may also be a factor in reproductive abnormalities such as amenorrhea and polycystic ovarian disease (see [159] for a brief review). Although the role of melatonin in regulating seasonal and circadian rhythms in vertebrates is well known, melatonin has also been found to have an effect on osmoregulation in fish [160], bone resorption in mice [161], and cancer cell growth [162]. Melatonin regulation is partly controlled by light exposure of photoreceptors in the eye that are different from those photoreceptors active in photopic vision [163]. A variety of other molecules such as cortisol, thyroid hormones, growth hormone, sex hormones, and insulin interact with the sympathetic nervous system (SNS) and are intimately linked with the regulation of adipose tissue (fat) physiology and endocrine function [164].

The nervous and endocrine systems are quite potent in terms of the number and variety of physiological and regulatory processes that they affect or control. Most interestingly from the viewpoint of MEMS, however, is the fact that physical or chemical stimuli can interact with the nervous and endocrine systems to affect many of these processes in the body. This offers an opportunity to leverage MEMS technology for significant physiological impact. The delivery of hormones or other molecules that actuate a cascade of subsequent regulatory molecules in the body, for example, would allow for the possibility of MEMS to replace or augment certain systems in the body that are not functioning properly. This avenue of research is particularly appealing in light of the considerations that many of these hormones and other regulatory molecules are extremely potent (only small amounts of the molecules would be required for physiological effect), and that the timing of the molecule delivery is often crucial (a concern that MEMS technology is particularly suited to address). Extrapolating from the success of pacemakers, one can envision MEMS as a uniquely powerful platform for delivering potent therapeutic agents whose temporal administration is vital to their efficacy and whose effects are naturally amplified by the human body.

\section{CONCLUSION}

MEMS have many characteristics that make them appealing for biological applications, including the ability to control their physical and chemical characteristics on the micrometer and nanometer scale. Additionally, the exact temporal control that can be achieved over MEMS operation makes the devices particularly attractive for drug delivery applications where precise dosing is required. The microchip for drug delivery developed in our laboratory [82], for example, is capable of pulsatile release of drugs by opening various reservoirs on command. The addition of hydrogels, biosensors, and other features that are responsive to the local environment of the device will allow MEMS to operate in a more closely integrated manner with the biological surroundings. Further, the application of MEMS technology in novel areas such as stent fabrication and immunoisolation capsules offers the potential for significant improvements in biological integration of a wide range of implantable devices. The growing interest in combining living cells with microfabricated devices, and in using microfabrication technology for tissue engineering and drug delivery, may ultimately lead the way to fully integrated, MEMS-based devices that could augment or replace entire biological systems in the human body.

\section{REFERENCES}

[1] G. T. A. Kovacs, N. I. Maluf, and K. E. Petersen, "Bulk micromachining of silicon," Proc. IEEE, vol. 86, pp. 1536-1551, Aug. 1998.

[2] J. M. Bustillo, R. T. Howe, and R. S. Muller, "Surface micromachining for microelectromechanical systems," Proc. IEEE, vol. 86, pp. 1552-1574, Aug. 1998.

[3] M. A. Schmidt, "Wafer-to-wafer bonding for microstructure formation,” Proc. IEEE, vol. 86, pp. 1575-1585, Aug. 1998. 
[4] J. A. Rogers, K. E. Paul, R. J. Jackman, and G. M. Whitesides, "Using an elastomeric phase mask for sub-100 nm photolithography in the optical near field," Appl. Phys. Lett., vol. 70, pp. 2658-2660, 1997.

[5] J. Kost, K. Leong, and R. Langer, "Ultrasound-enhanced polymer degradation and release of incorporated substances," Proc. Nat. Acad. Sci., vol. 86, pp. 7663-7666, 1989.

[6] M. A. Wheatley, D. El-Sherif, R. Basude, R. Shimp, and P. Narayan, "Ultrasound-triggered drug delivery with contrast imaging: Effect of microencapsulation method," in Proc. Materials Research Soc. Symp., vol. 550, 1999, pp. 113-118.

[7] A. M. Lowman, M. Morishita, M. Kajita, T. Nagai, and N. A. Peppas, "Oral delivery of insulin using $\mathrm{pH}$-responsive complexation gels," $J$. Pharm. Sci., vol. 88, pp. 933-937, 1999.

[8] J. Taillefer, M.-C. Jones, N. Brasseur, J. E. Van Lier, and J.-C. Leroux, "Preparation and characterization of $\mathrm{pH}$-responsive polymeric micelles for the delivery of photosensitizing anticancer drugs," J. Pharm. Sci., vol. 89, pp. 52-62, 2000.

[9] O. V. Gerasimov, J. A. Boomer, M. M. Qualls, and D. H. Thompson, "Cytosolic drug delivery using $\mathrm{pH}$ - and light-sensitive liposomes," Adv. Drug Delivery Rev., vol. 38, pp. 317-338, 1999.

[10] L.-C. Dong, Q. Yan, and A. S. Hoffman, "Controlled release of amylase from a thermal and $\mathrm{pH}$-sensitive, macroporous hydrogel," $J$. Controlled Release, vol. 19, pp. 171-178, 1992.

[11] R. Sutinen, V. Laasanen, P. Paronen, and A. Urtti, "pH-controlled silicone microspheres for controlled drug delivery," J. Controlled Release, vol. 33, pp. 163-171, 1995.

[12] K. Kataoka, H. Koyo, and T. Tsuruta, "Novel pH-sensitive hydrogels of segmented poly(amine ureas) having a repetitive array of polar and apolar units in the main chain," Macromolecules, vol. 28, pp. 3336-3341, 1995.

[13] A. S. Hoffman, A. Afrassiabi, and L. C. Dong, "Thermally reversible hydrogels: II. Delivery and selective removal of substances from aqueous solutions," J. Controlled Release, vol. 4, pp. 213-222, 1986.

[14] D. Needham and M. W. Dewhirst, "The development and testing of a new temperature-sensitive drug delivery system for the treatment of solid tumors," Adv. Drug Delivery Rev., vol. 53, pp. 285-305, 2001.

[15] L. E. Bromberg and E. S. Ron, "Temperature-responsive gels and thermogelling polymer matrices for protein and peptide delivery," Adv. Drug Delivery Rev., vol. 31, pp. 197-221, 1998.

[16] Y. M. Lee, S. H. Kim, and C. S. Cho, "Synthesis and swelling characteristics of $\mathrm{pH}$ and thermoresponsive interpenetrating polymer network hydrogel composed of poly(vinyl alcohol) and poly(acrylic acid)," J. Appl. Polym. Sci., vol. 62, pp. 301-311, 1996.

[17] Y. H. Bae, T. Okano, R. Hsu, and S. W. Kim, "Thermo-sensitive polymers as on-off switches for drug release," Makromol. Chem., Rapid Commun., vol. 8, pp. 481-485, 1987.

[18] J. E. Chung, M. Yokoyama, M. Yamato, T. Aoyagi, Y. Sakurai, and T. Okano, "Thermo-responsive drug delivery from polymeric micelles constructed using block copolymers of poly( $N$-isopropylacrylamide) and poly(butylmethacrylate)," J. Controlled Release, vol. 62, pp. 115-127, 1999.

[19] X. Cao, S. Lai, and L. J. Lee, "Design of a self-regulated drug delivery device," Biomed. Microdev., vol. 3, pp. 109-118, 2001.

[20] T. Miyata, T. Uragami, and K. Nakamae, "Biomolecule-sensitive hydrogels," Adv. Drug Delivery Rev., vol. 54, pp. 79-98, 2002.

[21] K. Kataoka, H. Miyazaki, M. Bunya, T. Okano, and Y. Sakurai, "Totally synthetic polymer gels responding to external glucose concentration: Their preparation and application to on-off regulation of insulin release," J. Amer. Chem. Soc., vol. 120, pp. 12694-12 695, 1998.

[22] M. J. Tierney and C. R. Martin, "New electrorelease systems based on microporous membranes," J. Electrochem. Soc., vol. 137, pp. 3789-3793, 1990

[23] S. Kagatani, T. Shinoda, Y. Konno, M. Fukui, T. Ohmura, and Y. Osada, "Electroresponsive pulsatile depot delivery of insulin from poly (dimethylaminoproplyacrylamide) gel in rats," J. Pharm. Sci., vol. 86, pp. 1273-1277, 1997.

[24] S. H. Yuk, S. H. Cho, and H. B. Lee, "Electric current-sensitive drug delivery systems using sodium alginate/polyacrylic acid composites," Pharm. Res., vol. 9, pp. 955-957, 1992.

[25] K. Sawahata, M. Hara, H. Yasunaga, and Y. Osada, "Electrically controlled drug delivery systems using polyelectrolyte gels," J. Controlled Release, vol. 14, pp. 253-262, 1990.

[26] I. C. Kwon, Y. H. Bae, and S. W. Kim, "Electrically erodible polymer gel for controlled release of drugs," Nature, vol. 354, pp. 291-293, 1991.
[27] Y. H. Bae, I. C. Kwon, and S. W. Kim, "Pulsatile drug release by electric stimulus," in Polymeric Drugs and Drug Administration. ser. ACS Symp. Series 545, R. M. Ottenbrite, Ed. Washington, DC: ACS, 1994, pp. 98-110.

[28] E. R. Edelman, J. Kost, H. Bobeck, and R. Langer, "Regulation of drug release from polymer matrices by oscillating magnetic fields," J. Biomed. Mater. Res., vol. 19, pp. 67-83, 1985.

[29] J. Kost, J. Wolfrum, and R. Langer, "Magnetically enhanced insulin release in diabetic rats," J. Biomed. Mater. Res., vol. 21, pp. 1367-1373, 1987.

[30] R. F. Service, "Can sensors make a home in the body?," Science, vol. 297, pp. 962-963, 2002.

[31] P. U. Abel and T. von Woedtke, "Biosensors for in vivo glucose measurement: Can we cross the experimental stage," Biosens. Bioelectron., vol. 17, pp. 1059-1070, 2002.

[32] D. A. Gough and J. C. Armour, "Development of the implantable glucose sensor: What are the prospects and why is it taking so long?," Diabetes, vol. 44, pp. 1005-1009, 1995.

[33] M. E. Meyerhoff, "In vivo blood-gas and electrolyte sensors: Progress and challenges," Trends Anal. Chem., vol. 12, pp. 257-265, 1993.

[34] E. W. Kraegen and D. J. Chisholm, "Closure of the loop by glucose sensing-Physiological and practical considerations," Horm. Metab. Res., vol. 20, pp. 1-4, 1988. Suppl. S.

[35] R. J. McNichols and G. L. Coté, "Optical glucose sensing in biological fluids: An overview," J. Biomed. Opt., vol. 5, pp. 5-16, 2000.

[36] B. Ziaie and K. Najafi, "An implantable microsystem for tonometric blood pressure measurement," Biomed. Microdev., vol. 3, pp. 285-292, 2001.

[37] C. A. Grimes and D. Kouzoudis, "Thin-film magnetoelastic microsensors for remote query biomedical monitoring," Biomed. Microdev., vol. 2, pp. 51-60, 1999.

[38] D. A. Gough, "Issues related to in vitro operation of potentially implantable enzyme electrode glucose sensors," Horm. Metab. Res., vol. 20, pp. 30-33, 1988. Suppl. S.

[39] W. K. Ward, L. B. Jansen, E. Anderson, G. Reach, J. Klein, and G. S. Wilson, "A new amperometric glucose microsensor: In vitro and short-term in vivo evaluation," Biosens. Bioelectron., vol. 17 pp. 181-189, 2002.

[40] S. A. Grant, K. Bettercourt, P. Krulevitch, J. Hamilton, and R. Glass, "In vitro and in vivo measurements of fiber optic and electrochemical sensors to monitor brain tissue pH," Sens. Actuators, B, vol. 72, pp. 174-179, 2001.

[41] S. A. Grant and R. S. Glass, "Sol-gel based fiber optic pH sensor," in Proc. SPIE, Biomedical Sensing, Imaging, and Tracking Technologies II, vol. 2976, 1997, pp. 64-70.

[42] E. Jauniaux, A. Watson, O. Ozturk, D. Quick, and G. Burton, "In vivo measurement of intrauterine gases and acid-base values early in human pregnancy," Human Reproduction, vol. 14, pp. 2901-2904, 1999.

[43] K. Stangel, S. Kolnsberg, D. Hammerschmidt, B. J. Hosticka, H. K. Trieu, and W. Mokwa, "A programmable intraocular CMOS pressure sensor system implant," IEEE J. Solid-State Circuits, vol. 36, pp. 1094-1100, July 2001.

[44] B. Zhao and J. S. Moore, "Fast pH- and ionic strength-responsive hydrogels in microchannels," Langmuir, vol. 17, pp. 4758-4763.

[45] I. S. Han, M. Han, J. Kim, S. Lew, Y. J. Lee, F. Horkay, and J. J. Magda, "Constant-volume hydrogel osmometer: A new device concept for miniature biosensors," Biomacromolecules, vol. 3, pp. 1271-1275, 2002.

[46] D. J. Beebe, J. S. Moore, J. M. Bauer, Q. Yu, R. H. Liu, C. Devadoss, and B.-H. Jo, "Functional hydrogel structures for autonomous flow control inside microfluidic channels," Nature, vol. 404, pp. 588-590.

[47] D. T. Eddington, R. H. Liu, J. S. Moore, and D. J. Beebe, "An organic self-regulating microfluidic system," Lab. Chip, vol. 1, pp. 96-99, 2001.

[48] R. H. Liu, Q. Yu, and D. J. Beebe, "Fabrication and characterization of hydrogel-based microvalves," J. Microelectromech. Syst., vol. 11, pp. 45-53, 2002.

[49] S. K. De, N. R. Aluru, B. Johnson, W. C. Crone, D. J. Beebe, and J. Moore, "Equilibrium swelling and kinetics of $\mathrm{pH}$-responsive hydrogels: Models, experiments, and simulations," J. Microelectromech. Syst., vol. 11, pp. 544-555, 2002.

[50] Y. Gu, A. Baldi, B. Ziaie, and R. A. Siegel, "Modulation of drug delivery rate by hydrogel-incorporating MEMS devices," in Proc. 2nd Annu. Int. IEEE-EMBS Special Topic Conf. Microtechnologies Medicine and Biology, 2002, pp. 406-409. 
[51] Z. A. Strong, A. W. Wang, and C. F. McConaghy, "Hydrogel-actuated capacitive transducer for wireless biosensors," Biomed. $\mathrm{Mi}$ crodev., vol. 4, pp. 97-103, 2002.

[52] Q. Yu, J. M. Bauer, J. S. Moore, and D. J. Beebe, "Fabrication and characterization of a biomimetic hydrogel check valve," in Proc. 1st Annu. Int. IEEE-EMBS Special Topic Conf. Microtechnologies Medicine and Biology, 2000, pp. 336-339.

[53] Q. Yu, J. M. Bauer, and J. S. Moore, "Responsive biomimetic hydrogel valve for microfluidics," Appl. Phys. Lett., vol. 78, pp. 2589-2591, 2001.

[54] M. J. Bassetti, J. S. Moore, and D. J. Beebe, "Development of electrically triggered hydrogels for microfluidic applications," in 2nd Annu. Int. IEEE-EMBS Special Topic Conf. Microtechnologies Medicine and Biology, Madison, WI, May 2-4, 2002, pp. 410-413.

[55] M. J. Madou, Fundamentals of Microfabrication. Boca Raton, FL: CRC Press, 2002.

[56] H. L. Kim, M. Madou, and J. Hines, "Telemetric ion-selective electrodes," Polym. Mater. Sci. Eng., vol. 70, pp. 133-134, 1994.

[57] M. Schwarz, R. Hauschild, B. J. Hosticka, J. Huppertz, T. Kneip, S. Kolnsberg, L. Ewe, and H. K. Trieu, "Single-chip CMOS image sensors for a retina implant system," IEEE Trans. Circuits Syst. II, vol. 46, pp. 870-877, July 1999.

[58] M. Schwarz, L. Ewe, R. Hauschild, B. J. Hosticka, J. Huppertz, S. Kolnsberg, W. Mokwa, and H. K. Trieu, "Single chip CMOS imagers and flexible microelectronic stimulators for a retina implant system," Sens. Actuators, A, vol. 83, pp. 40-46, 2000.

[59] J. J. Ho, Y. K. Fang, M. C. Hsieh, S. F. Ting, G. S. Chen, M. S. Ju, T. Y. Chen, C. R. Huang, and C. Y. Chen, "Development of a microelectromechanical system pressure sensor for rehabilitation engineering applications," Int. J. Electron., vol. 87, pp. 757-767, 2000.

[60] M. C. Hsieh, Y. K. Fang, M. S. Ju, G. S. Chen, J. J. Ho, C. H. Yang, P. M. Wu, G. S. Wu, and T. Y. Chen, "A contact-type piezoresistive micro-shear stress sensor for above-knee prosthesis application," $J$. Microelectromech. Syst., vol. 10, pp. 121-127, Mar. 2001.

[61] L. Wang and D. J. Beebe, "Characterization of a silicon-based shearforce sensor on human subjects," IEEE Trans. Biomed. Eng., vol. 49, pp. 1340-1347, Nov. 2002

[62] D. J. Wirthlin, F. Alcocer, D. Whitley, and W. D. Jordan, "Use of hybrid aortic stent grafts for endovascular repair of abdominal aortic aneurysms: Indications and outcomes," J. Surg. Res., vol. 108, pp. 14-19, 2002

[63] B. L. Hiatt, F. Ikeno, A. C. Yeung, and A. J. Carter, "Drug-eluting stents for the prevention of restenosis: In quest for the holy grail," Catheter. Cardiovasc. Interv., vol. 55, pp. 409-417, 2002.

[64] W. J. van der Giessen, A. M. Lincoff, R. S. Schwartz, H. M. M. van Beusekom, P. W. Serruys, D. R. Holmes, S. G. Ellis, and E. J. Topol, "Marked inflammatory sequelae to implantation of biodegradable and nonbiodegradable polymers in porcine coronary arteries," Circulation, vol. 94, pp. 1690-1697, 1996.

[65] A. W. Heldman, L. Cheng, G. M. Jenkins, P. F. Heller, D.-W. Kim, M. Ware, C. Nater, R. H. Hruban, B. Rezai, B. S. Abella, K. E. Bunge, J. L. Kinsella, S. J. Sollot, E. G. Lakatta, J. A. Brinker, W. L. Hunter, and J. P. Froehlich, "Paclitaxel stent coating inhibits neointimal hyperplasia at 4 weeks in a porcine model of coronary restenosis," Circulation, vol. 103, pp. 2289-2295, 2001.

[66] M. Oberhoff, C. Herdeg, A. Baumbach, and K. R. Karsch, "Stentbased antirestenotic coatings (sirolimus/paclitaxel)," Catheter. Cardiovasc. Interv., vol. 55, pp. 404-408, 2002.

[67] M. A. Morice, P. W. Serruys, J. E. Sousa, J. Fajadet, E. B. Hayashi, M. Perin, A. Colombo, G. Schuler, P. Barragan, G. Guagliumi, F. Molnar, and R. Falotico, "A randomized comparison of a sirolimuseluting stent with a standard stent for coronary revascularization," N. Eng. J. Med., vol. 23, pp. 1773-1780, 2002.

[68] M. Degertekin, P. W. Serruys, D. P. Foley, K. Tanabe, E. Regar, J. Vos, P. C. Smits, W. J. van der Giessen, M. van den Brand, P. de Feyter, and J. J. Popma, "Persistent inhibition of neointimal hyperplasia after sirolimus-eluting stent implantation: Long-term (up to 2 years) clinical, angiographic, and intravascular ultrasound follow-up," Circulation, vol. 106, pp. 1610-1613, 2002.

[69] E. Grube, U. Gerckens, S. Rowold, R. Muller, G. Selbach, J. Stamm, and M. Staberock, "Inhibition of in-stent restenosis by the Quanam drug eluting polymer stent; Two year follow-up," J. Amer. Coll. Cardiol., vol. 37, p. 74A, 2001. Suppl. A.

[70] Y. Nakayama, K. Ji-Youn, S. Nishi, H. Ueno, and T. Matsuda, "Development of high-performance stent: Gelatinous photogel-coated stent that permits drug delivery and gene transfer," J. Biomed. Mater. Res., vol. 57, pp. 559-566, 2001.
[71] Coronary stent platform, Conor Medsystems. (2002). [Online]. Available: www.conormed.com/coronarystentplatform.shtml

[72] S. Windecker, I. Mayer, G. DePasquale, W. Maier, O. Dirsch, P. De Groot, Y.-P. Wu, G. Noll, B. Leskosek, B. Meier, and O. M. Hess, "Stent coating with titanium-nitride-oxide for reduction of neointimal hyperplasia," Circulation, vol. 104, pp. 928-933.

[73] M. L. Reed, C. Wu, J. Kneller, S. Watkins, D. A. Vorp, A. Nadeem, L. E. Weiss, K. Rebello, M. Mescher, A. J. C. Smith, W. Rosenblum, and M. D. Feldman, "Micromechanical devices for intravascular drug delivery,” J. Pharm. Sci., vol. 87, pp. 1387-1394, 1998.

[74] T. A. Desai, D. J. Hansford, L. Kulinsky, A. H. Nashat, G. Rasi, J. Tu, Y. Wang, M. Zhang, and M. Ferrari, "Nanopore technology for biomedical applications," Biomed. Microdev., vol. 2, pp. 11-40, 1999.

[75] T. A. Desai, W. H. Chu, G. Rasi, P. Sinibaldi-Vallebona, P. Borboni, G. Beattie, A. Hayek, and M. Ferrari, "Implantation of microfabricated immunoisolating biocapsules," in Proc. SPIE, Micro and Nanofabricated Electro-Optical-Mechanical Systems for Biomedical and Environmental Application, vol. 3258, 1998, pp. 40-47.

[76] T. A. Desai, W. H. Chu, G. Rasi, P. Sinibaldi-Vallebona, E. Guarino, and M. Ferrari, "Microfabricated biocapsules provide short-term immunoisolation of insulinoma xenografts," Biomed. Microdev., vol. 1, pp. 131-138, 1999.

[77] T. A. Desai, D. Hansford, and M. Ferrari, "Characterization of micromachined silicon membranes for immunoisolation and bioseparation applications," J. Membr. Sci., vol. 159, pp. 221-231, 1999.

[78] L. Leoni, A. Boiarski, and T. A. Desai, "Characterization of nanoporous membranes for immunoisolation: Diffusion properties and tissue effects," Biomed. Microdev., vol. 4, pp. 131-139, 2002.

[79] A. Ahmed, C. Bonner, and T. A. Desai, "Bioadhesive microdevices for drug delivery: A feasibility study," Biomed. Microdev., vol. 3, pp. 89-95, 2001

[80] — - "Bioadhesive microdevices with multiple reservoirs: A new platform for oral drug delivery," J. Controlled Release, vol. 81, pp. 291-306, 2002.

[81] F. J. Martin and C. Grove, "Microfabricated drug delivery systems: Concepts to improve clinical benefit," Biomed. Microdev., vol. 3, pp. 97-108, 2001.

[82] J. T. Santini, M. J. Cima, and R. Langer, "A controlled-release microchip," Nature, vol. 397, pp. 335-338, 1999.

[83] J. T. Santini Jr., A. C. Richards, R. A. Scheidt, M. J. Cima, and R. Langer, "Microchips as controlled drug delivery devices," Angew. Chem. Int. Ed., vol. 39, pp. 2396-2407, 2000.

[84] R. A. Scheidt, J. T. Santini, A. C. Richards, A. M. Johnson, A. Rosenberg, M. J. Cima, and R. Langer, "Microchips as implantable drug delivery devices," in Proc. 1st Annu. Int. IEEE-EMBS Special Topic Conf. Microtechnologies Medicine and Biology, 2000, pp. 483-486.

[85] M. J. Cima, "Drug release from an implantable MEMS array," presented at the ACS ProSpectives Future Directions of Drug Delivery Technologies: Molecular Design, Cellular Response and Nanotechnology Conf., Boston, MA, 2002.

[86] Y. Li, R. S. Shawgo, R. Langer, and M. J. Cima, "Electrochemical disintegration of gold membranes on a MEMS device for drug delivery," presented at the 2002 Fall Materials Research Society Meeting, Boston, MA.

[87] — "Mechanical testing of gold membranes on a MEMS device for drug delivery," in Proc. 2nd Annu. Int. IEEE-EMBS Special Topic Conf. Microtechnologies Medicine and Biology, 2002, pp. 390-393.

[88] R. J. Jackman, D. C. Duffy, E. Ostuni, N. D. Willmore, and G. M. Whitesides, "Fabricating large arrays of microwells with arbitrary dimensions and filling them using discontinuous dewetting," Anal. Chem., vol. 70, pp. 2280-2287, 1998.

[89] D. K. Armani and C. Liu, "Microfabrication technology for polycaprolactone, a biodegradable polymer," J. Micromech. Microeng. , vol. 10 , pp. 80-84, 2000.

[90] V. V. Kancharla and S. Chen, "Fabrication of biodegradable polymeric micro-devices using laser micromachining," Biomed. Microdev., vol. 4, pp. 105-109, 2002.

[91] D. V. McAllister, M. G. Allen, and M. R. Prausnitz, "Microfabricated microneedles for gene and drug delivery," Annu. Rev. Biomed. Eng., vol. 2, pp. 289-313, 2000.

[92] M. R. Prausnitz, "Overcoming skin's barrier: The search for effective and user-friendly drug delivery," Diab. Technol. Ther., vol. 3, pp. 233-236, 2001.

[93] S. Henry, D. V. McAllister, M. G. Allen, and M. R. Prausnitz, "Microfabricated microneedles: A novel approach to transdermal drug delivery," J. Pharm. Sci., vol. 87, pp. 922-925, 1998. 
[94] S. Kaushik, A. H. Hord, D. D. Denson, D. V. McAllister, S. Smitra, M. G. Allen, and M. R. Prausnitz, "Lack of pain associated with microfabricated microneedles," Anesth. Analg., vol. 92, pp. 502-504, 2001.

[95] W. Q. Lin, M. Cormier, A. Samiee, A. Griffin, B. Johnson, C.-L. Teng, G. E. Hardee, and P. E. Daddona, "Transdermal delivery of antisense oligonucleotides with microprojection patch (Macroflux) technology," Pharm. Res., vol. 18, pp. 1789-1793, 2001.

[96] J. A. Matriano, M. Cormier, J. Johnson, W. A. Young, M. Buttery, K. Nyam, and P. E. Daddona, "Macroflux microprojection array patch technology: A new and efficient approach for intracutaneous immunization," Pharm. Res., vol. 19, pp. 63-70, 2002.

[97] P. R. Troyk, "Injectable electronic identification, monitoring, and stimulation systems," Annu. Rev. Biomed. Eng., vol. 1, pp. 177-209, 1999.

[98] T. A. Milheiser, "Identification System,", 1998.

[99] G. E. Loeb, R. A. Peck, W. H. Moore, and K. Hood, "BION system for distributed neural prosthetic interfaces," Med. Eng. Phy., vol. 23, pp. 9-18, 2001.

[100] B. Ziaie, M. D. Nardin, A. R. Coghlan, and K. Najafi, "A singlechannel implantable microstimulator for functional neuro-muscular stimulation," IEEE Trans. Biomed. Eng., vol. 44, pp. 909-920, Oct. 1997.

[101] D. F. Williams, Williams Dictionary of Biomaterials, Liverpool, U.K.: Liverpool Univ. Press, 1999.

[102] G. Kotzar, M. Freas, P. Abel, A. Fleischman, S. Roy, C. Zorman, J. M. Moran, and J. Melzak, "Evaluation of MEMS materials of construction for implantable medical devices," Biomaterials, vol. 23, pp. 2737-2750, 2002.

[103] G. Voskerician, M. S. Shive, R. S. Shawgo, H. von Recum, J. M. Anderson, M. J. Cima, and R. Langer, "Biocompatibility and biofouling of MEMS drug delivery device," Biomaterials, vol. 24, pp. 1959-1967, 2003.

[104] P. R. Hernandez, C. Taboada, L. Leija, V. Tsutsumi, B. Vazquez, F. Valdes-Perezgasga, and J. L. Reyes, "Evaluation of biocompatibility of pH-ISFET materials during long-term subcutaneous implantation," Sens. Actuators, B, vol. 46, pp. 133-138, 1998.

[105] D. J. Edell, V. van Toi, V. M. McNeil, and L. D. Clark, "Factors influencing the biocompatibility of insertable silicon microshafts in cerebral cortex," IEEE Trans. Biomed. Eng., vol. 39, pp. 635-643, June 1992.

[106] J. N. Turner, W. Shain, D. H. Szarowski, M. Anderson, S. Martins, M. Isaacson, and H. Craighead, "Cerebral astrocyte response to micromachined silicon implants," Exp. Neurol., vol. 156, pp. 33-49, 1999.

[107] B. W. Kristensen, J. Noraberg, P. Theibaud, M. Koudelka-Hep, and J. Zimmer, "Biocompatibility of silicon-based arrays of electrodes coupled to organotypic hippocampal brain slice cultures," Brain Res., vol. 896, pp. 1-17, 2001.

[108] T. A. Desai, W. H. Chu, J. Tu, P. Shrewsbury, and M. Ferrari, "Microfabricated biocapsules for cell xenografts: A review," in Proc. SPIE, Micro and Nanofabricated Electro-Optical-Mechanical Systems for Biomedical and Environmental Application, vol. 2978, 1997, pp. 216-226.

[109] A. Rosengren, L. Wallman, N. Danielsen, T. Laurell, and L. M. Bjursten, "Tissue reactions evoked by porous and plane surfaces made out of silicon and titanium," IEEE Trans. Biomed. Eng., vol. 49, pp. 392-398, Apr. 2002.

[110] L. T. Canham, "Bioactive silicon structures fabrication through nanoetching techniques," Adv. Mater., vol. 7, pp. 1033-1037, 1995.

[111] L. T. Canham, C. L. Reeves, J. P. Newey, M. R. Houlton, T. I. Cox, J. M. Buriak, and M. P. Stewart, "Derivatized mesoporous silicon with dramatically improved stability in simulated human blood plasma," Adv. Mater., vol. 11, pp. 1505-1507, 1999.

[112] L. T. Canham, C. L. Reeves, D. O. King, P. J. Branfield, J. G. Crabb, and M. C. L. Ward, "Bioactive polycrystalline silicon," Adv. Mater, vol. 8, pp. 850-853, 1996.

[113] A. Pistorius and B. Willershausen, "Biocompatibility of dental materials in two human cell lines," Eur. J. Med. Res., vol. 7, pp. 81-88, 2002.

[114] F. Widu, D. Drescher, R. Junker, and C. Bourauel, "Corrosion and biocompatibility of orthodontic wires," J. Mater. Sci. Mater. Med., vol. 10, pp. 275-281, 1999.

[115] J. M. Meyer and L. Reclaru, "Electrochemical determination of the corrosion resistance of noble metal dental casting alloys," J. Mater. Sci. Mater. Med., vol. 6, pp. 534-540, 1995.
[116] N. Holmstrom, P. Nilsson, J. Carlsten, and S. Bowald, "Long term in vivo experience of an electrochemical sensor using the potential step technique for measurement of mixed venous oxygen pressure," Biosens. Bioelectronics, vol. 13, pp. 1287-1295, 1998.

[117] M. H. Schoenfisch, M. Ovadia, and J. E. Pemberton, "Covalent surface chemical modification of electrodes for cardiac pacing applications," J. Biomed. Mater. Res., vol. 51, pp. 209-215, 2000.

[118] G. Voskerician, R. S. Shawgo, A. P. Hiltner, J. M. Anderson, M. J. Cima, and R. Langer, "In vivo inflammatory and wound healing effects of gold electrode voltammetry for MEMS micro-reservoir drug delivery device," IEEE Trans. Biomed. Eng., to be published.

[119] A. S. Blawas and W. M. Reichert, "Protein patterning," Biomaterials, vol. 19, pp. 595-609, 1998.

[120] P. Kingshott and H. J. Griesser, "Surfaces that resist bioadhesion," Curr. Opin. Solid State Mater. Sci., vol. 4, pp. 403-412, 1999.

[121] L. H. Dubois and R. G. Nuzzo, "Synthesis, structure, and properties of model organic surfaces," Annu. Rev. Phys. Chem., vol. 43, pp. 437-463, 1992.

[122] S. Sharma, K. C. Popat, and T. A. Desai, "Controlling nonspecific protein interactions in silicon biomicrosystems with nanostructured poly (ethylene glycol) films," Langmuir, vol. 18, pp. 8728-8731, 2002.

[123] Y. Hanein, Y. V. Pan, B. D. Ratner, D. D. Denton, and K. F. Bohringer, "Micromachining of nonfouling coatings for bio-MEMS (micro electro mechanical systems) applications," Sens. Actuators $B$, vol. B81, pp. 49-54, 2001.

[124] A. Papra, A. Bernard, D. Juncker, N. B. Larsen, B. Michel, and E. Delamarche, "Microfluidic networks made of poly (dimethylsiloxane), $\mathrm{Si}$, and Au coated with polyethylene glycol for patterning proteins onto surfaces," Langmuir, vol. 17, pp. 4090-4095, 2001.

[125] G. M. B. F. Snellings, S. O. Vansteenkiste, S. I. Corneillie, M. C. Davies, and E. H. Schacht, "Protein adhesion at poly (ethylene glycol) modified surfaces," Adv. Mater., vol. 12, pp. 1959-1962, 2000.

[126] M. Shen, M. S. Wagner, D. G. Castner, B. D. Ratner, and T. A. Horbett, "Multivariate surface analysis of plasma-deposited tetraglyme for reduction of protein adsorption and monocyte adhesion," Langmuir, vol. 19, pp. 1692-1699, 2003.

[127] J. P. Bearinger, D. G. Castner, S. L. Golledge, A. Rezania, S. Hubchak, and K. E. Healy, "P(AAm-co-EG) interpenetrating polymer networks grafted to oxide surfaces: Surface characterization, protein adsorption, and cell detachment studies," Langmuir, vol. 13, pp. 5175-5183, 1997.

[128] G. L. Kenausis, J. Voeroes, D. L. Elbert, N. Huang, R. Hofer, L. Ruiz-Taylor, M. Textor, J. A. Hubbell, and N. D. Spencer, "Poly (L-lysine)-g-poly (ethylene glycol) layers on metal oxide surfaces: Attachment mechanism and effects of polymer architecture on resistance to protein adsorption," J. Phys. Chem. B., vol. 104, pp. 3298-3309, 2000.

[129] K. L. Prime and G. M. Whitesides, "Self-assembled organic monolayers: Model systems for studying adsorption of proteins at surfaces," Science, vol. 252, pp. 1164-1167, 1991.

[130] E. Ostuni, R. G. Chapman, R. E. Holmlin, S. Takayama, and G. M. Whitesides, "A survey of structure-property relationships of surfaces that resist the adsorption of protein," Langmuir, vol. 17, pp. 5605-5620, 2001.

[131] M. Zhang, T. Desai, and M. Ferrari, "Proteins and cells on PEG immobilized silicon surfaces," Biomaterials, vol. 19, pp. 953-960, 1998.

[132] J. D. Cox, M. S. Curry, S. K. Skirboll, P. L. Gourley, and D. Y. Sasaki, "Surface passivation of a microfluidic device to glial cell adhesion: A comparison of hydrophobic and hydrophilic SAM coatings," Biomaterials, vol. 23, pp. 929-935, 2001.

[133] K. Kim, C. Kim, and Y. Byun, "Preparation of a dipalmitoylphosphatidylcholine/cholesterol Langmuir-Blodgett monolayer that suppresses protein adsorption," Langmuir, vol. 17, pp. 5066-5070, 2001.

[134] R. Vaidya, L. M. Tendev, G. Bradley, M. J. O’Brien II, M. Cone, and G. P. López, "Computer-controlled laser ablation: A convenient and versatile tool for micropatterning biofunctional synthetic surfaces for applications in biosensing and tissue engineering," Biotechnol. Prog., vol. 14, pp. 371-377, 1998.

[135] J. Voldman, M. L. Gray, and M. A. Schmidt, "Microfabrication in biology and medicine," Annu. Rev. Biomed. Eng., vol. 1, pp. 401-425, 1999. 
[136] H. G. Craighead, C. D. James, and A. M. P. Turner, "Chemical and topographical patterning for directed cell attachment," Curr. Opin. Solid State Mater. Sci., vol. 5, pp. 177-184, 2001.

[137] A. C. Duncan, F. Weisbuch, F. Rouais, S. Lazare, and Ch. Baquey, "Laser microfabricated model surfaces for controlled cell growth," Biosens. Bioelectron., vol. 17, pp. 413-426, 2002.

[138] A. M. P. Turner, N. Dowell, S. W. P. Turner, L. Kam, M. Isaacson, J. N. Turner, H. G. Craighead, and W. Shain, "Attachment of astroglial cells to microfabricated pillar arrays of different geometries," $J$. Biomed. Mater. Res., vol. 51, pp. 430-441, 2000.

[139] R. Kapur, J. M. Calvert, and A. S. Rudolph, "Electrical, chemical, and topological addressing of mammalian cells with microfabricated systems," J. Biomech. Eng., vol. 121, pp. 65-72, 1999.

[140] S. Boateng, S. S. Lateef, C. Crot, D. Motlagh, T. Desai, A. M. Samarel, B. Russell, and L. Hanley, "Peptides bound to silicone membranes and 3D microfabrication for cardiac cell culture," $A d v$. Mater, vol. 14, pp. 461-463, 2002.

[141] J. Deutsch, D. Motlagh, B. Russell, and T. A. Desai, "Fabrication of microtextured membranes for cardiac myocyte attachment and orientation," J. Biomed. Mater. Res., vol. 53, pp. 267-275, 2000.

[142] A. Folch, S. Mezzour, M. Düring, O. Hurtado, M. Toner, and R. Müller, "Stacks of microfabricated structures as scaffolds for cell culture and tissue engineering," Biomed. Microdev., vol. 2, pp. 207-214, 2000.

[143] M. J. Powers, K. Domansky, M. R. Kaazempur-Mofrad, A. Kalezi, A. Capitano, A. Upadhyaya, P. Kurzawski, K. E. Wack, D. B. Stolz, R. Kamm, and L. G. Griffith, "A microfabricated array bioreactor for perfused 3D liver culture," Biotechnol. Bioeng., vol. 78, pp. 257-269, 2002.

[144] J. T. Borenstein, H. Terai, K. R. King, E. J. Weinberg, M. R. Kaazempur-Mofrad, and J. P. Vacanti, "Microfabrication technology for vascularized tissue engineering," Biomed. Microdev., vol. 4, pp. 167-175, 2002.

[145] D. L. Hayes, "Evolving indications for permanent pacing," Amer. J. Cardiol., vol. 83, pp. 161D-165D, 1999.

[146] J. Werner, M. Meine, K. Hoeland, M. Hexamer, and A. Kloppe, "Sensor and control technology for cardiac pacing," Trans. Inst. Measure. Contr., vol. 22, pp. 289-302, 2000.

[147] N. E. Fearnot and H. J. Smith, "Survey of a new era in cardiac pacing: Automatic rate modulation," J. Clin. Eng., vol. 14, pp. 225-231, 1989.

[148] M. Gilkson and D. L. Hayes, "Recent advances in cardiac pacing," Curr. Opin. Cardiol., vol. 9, pp. 65-74, 1994.

[149] — - "Cardiac pacing, a review," Med. Clin. North Amer., vol. 85, pp. 369-421, 2001.

[150] D. L. Hayes, "The next 5 years in cardiac pacemakers: A preview," Mayo Clin. Proc., vol. 67, pp. 379-384, 1992.

[151] E. Alt, W. Combs, R. Willhaus, C. Condie, E. Bambl, P. Fotuhi, J. Pache, and A. Schomig, "A comparative study of activity and dual sensor: Activity and minute ventilation pacing responses to ascending and descending stairs," Pacing Clin. Electrophysiol., vol. 21, pp. 1862-1868, 1998.

[152] N. Saoudi, U. Appl, F. Anselme, M. Voglimacci, and A. Cribier, "How smart should pacemakers be?," Amer. J. Cardiol., vol. 83, pp. 180D-186D, 1999.

[153] M. Schaldach, "Automaticity in rate adaptive cardiac pacing," Proc. 18th Annu. Int. Conf. IEEE Engineering Medicine and Biology Society: Bridging Disciplines for Biomedicine, vol. 5, pp. 1955-1956, 1996.

[154] B. R. Jones, J. Kim, Q. Zhu, J. P. Nelson, B. H. KenKnight, D. J. Lang, and A. Warren, "Future of bradyarrhythmia therapy systems: Automaticity," Amer. J. Cardiol., vol. 83, pp. 192D-201D, 1999.

[155] Z. Jaworski, W. Kuzmicz, M. Sadowski, D. Sarna, A. Walkanis, A. Wielgus, and A. Wojtasik, "VLSI implementation of fuzzy logic controllers for rate-adaptive pacemakers," in Proc. 1st Annu. Int. IEEE-EMBS Special Topic Conf. Microtechnologies Medicine and Biology, 2000, pp. 475-478.

[156] D. J. Christini, "Systems for real-time adaptive cardiac pacing," in Proc. 1st Joint BMES/EMBS Conference: Serving Humanity, Advancing Technology, vol. 1, 1999, p. 319.

[157] B. Norwak, "Taking advantages of sophisticated pacemaker diagnostics," Amer. J. Cardiol., vol. 83, pp. 172D-179D, 1999.

[158] R. S. Sanders, "Implantable pacemakers," Proc. IEEE, vol. 84, pp. 480-486, 1996.

[159] C. S. Mantzoros, "The role of leptin in human obesity and disease: A review of current evidence," Ann. Intern. Med., vol. 130, pp. 671-680, 1999.

[160] E. Kulczykowka, "A review of the multifunctional hormone melatonin and a new hypothesis involving osmoregulation," Rev. Fish Biol. Fisheries, vol. 11, pp. 321-330, 2002.

[161] H. Koyama, O. Nakade, Y. Takada, T. Kaku, and K.-H. W. Lau, "Melatonin at pharmacologic doses increases bone mass by suppressing resorption through down-regulation of the RANKL-mediated osteoclast formation and activation," J. Bone Miner. Res., vol. 17, pp. 1219-1229, 2002.

[162] S. M. Hill, T. L. Kiefer, K. Melancon, and S. R. Teplitzky, "Prevention and regression of breast cancer with the combination of melatonin and retinoic acid," FASEB J., vol. 14, p. A268, 2000.

[163] G. C. Brainard, J. P. Hanifin, J. M. Greeson, B. Byrne, G. Glickman, E. Gerner, and M. D. Rollag, "Action spectrum for melatonin regulation in humans: Evidence for a novel circadian photoreceptor," $J$. Neurosci., vol. 21, pp. 6405-6412, 2001.

[164] V. J. Lawrence and S. W. Coppack, "The endocrine function of the fat cell-regulation by the sympathetic nervous system," Horm. Metab. Res., vol. 32, pp. 453-467, 2000.

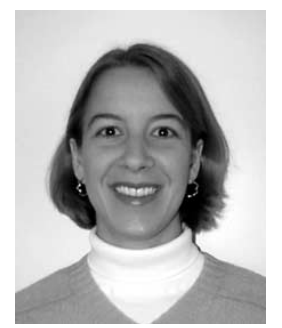

Amy C. Richards Grayson received the B.S. degree in materials science and engineering and the Ph.D. degree in polymer science in technology from the Department of Materials Science and Engineering, Massachusetts Institute of Technology, Cambridge (MIT) in 1997 and 2003, respectively.

She is currently studying RNA interference (RNAi) as a Postdoctoral Research Associate in the laboratory of Dr. D. Putnam at Cornell University, Ithaca, NY. Her doctoral research involved the integration of polymer science, polymer processing, and drug delivery technology to develop a novel polymeric controlled-release device, and to characterize the in vitro and in vivo performance, biodegradation, and biocompatibility of the device.

Ms. Grayson received a National Science Foundation Fellowship in 1997 and a Selected Professions Fellowship from the American Association of University Women in 2001.

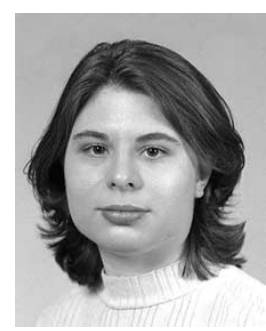

Rebecca Scheidt Shawgo received the B.S. degree in ceramic engineering (summa cum laude) from the University of Missouri, Rolla, in 1998. She is currently working toward the Ph.D. degree in the Department of Materials Science and Engineering at the Massachusetts Institute of Technology, Cambridge.

Her research focuses on the in vivo operation and biocompatibility of silicon microreservoir drug delivery devices.

dation Fellowship in 1999.

Ms. Shawgo received a National Science Foun-

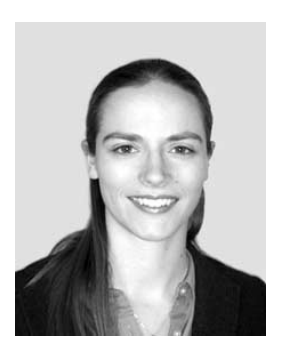

MEMS device.

Ms. Johnson received a National Science Foundation Fellowship in 1998 and a Merck/MIT Program Fellowship in 2001. 


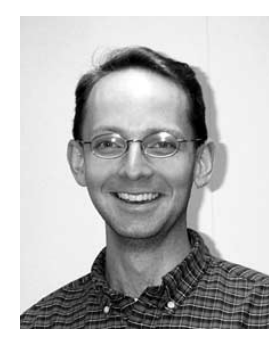

Nolan T. Flynn received the B.A. degree in chemistry from St. Olaf College, Northfield, MN in 1996 and the Ph.D. degree in chemistry from the University of Illinois, Urbana-Champaign, in 2001.

In 2001, he joined the laboratory of $\mathrm{Dr}$ R. Langer at the Massachusetts Institute of Technology, Cambridge (MIT) as a National Institutes of Health Postdoctoral Fellow and investigated surface modification methods and electrochemical behavior of MEMS drug delivery devices. He is currently an Assistant Professor of chemistry at Wellesley College, Wellesley, MA. His doctoral research concerned metallic nanoparticles using spectroscopic and electrochemical techniques. His current research interests are in the area of inorganic-organic hybrid materials.

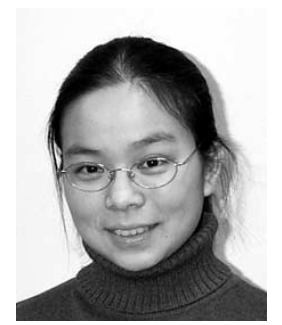

Yawen Li received both the B.S. and M.S degrees in materials science and engineering from Xi'an Jiaotong University, Xi'an, China. She is currently working toward the Ph.D. degree in the Department of Materials Science and Engineering at the Massachusetts Institute of Technology, Cambridge (MIT), working under the guidance of Prof. M. Cima.

Her research involves the microfabrication, mechanical, and electrochemical characterization of a drug delivery MEMS device.

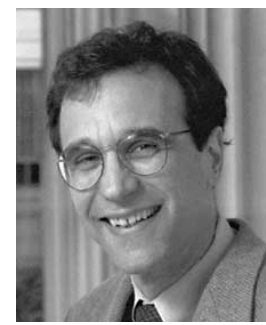

Michael J. Cima received the B.S. degree in chemistry and the Ph.D. degree in chemical engineering from the University of California, Berkeley, in 1982 and 1986, respectively.

$\mathrm{He}$ is currently the Sumitomo Electric Industries Professor in the Materials Science and Engineering Department at the Massachusetts Institute of Technology, Cambridge (MIT). His research interests include advanced forming technology, ceramic thin film processing, MEMS devices for medical electronics and drug delivery, and high throughput development methods for formulations of materials and pharmaceuticals. Forming methods for complex macro and micro devices are of particular interest, including MIT's three-dimensional printing process. His research group is one of the leaders in the development of chemically derived epitaxial oxide films for HTSC coated conductors. $\mathrm{He}$ and collaborators are developing implantable MEMS devices for unprecedented control in the delivery of pharmaceuticals. Most recently, his group has been working on methods to speed the development of materials systems that are based on complex formulations. His group is developing devices and processes that are employed in high throughput combinatorial screening of materials and pharmaceutical formulations.

Prof. Cima is a Fellow of the American Ceramics Society. He has received numerous honors, including the International Award of Materials Engineering for Resources, R\&D 100 Award, and the Alcoa Foundation Science Award.

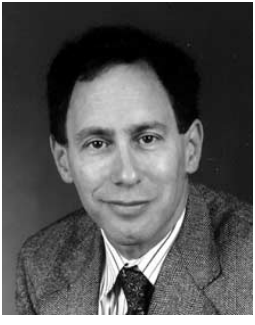

Robert S. Langer received the B.S. degree in chemical engineering from Cornell University, Ithaca, NY, in 1970 and the Sc.D. degree in chemical engineering from the Massachusetts Institute of Technology, Cambridge (MIT), in 1974. He has received honorary doctorates from ETH, Technion, Hebrew University, and Universite Catholique do Louvain.

He is currently the Kenneth J. Germeshausen Professor of Chemical and Biomedical Engineering at MIT. He has authored 725 articles and 420 abstracts, and has nearly 500 issued or pending patents.

Dr. Langer is one of very few people ever elected to all three U.S. national academies, and the youngest in history (at age 43 ) to receive this distinction. Forbes and Bio World have named him as one of the 25 most important individuals in biotechnology worldwide. Discover named him as one of the 20 most important people in biotechnology, and Forbes selected him as one of 15 innovators worldwide who will reinvent our future. Time and CNN named him as one of the 100 most important people in the United States and one of 18 top people in science or medicine in the United States. He has won over 100 major awards, including the National Academy of Engineering's Draper Prize, the Gairdner Foundation International Award, and the Lemelson-MIT Prize. 